\title{
Free Radical Oxidation and Antioxidant Status of Milk from Different Cow Breeds
}

\author{
Sergii Shapovalov ${ }^{1 *}$, Sergei Mikhaylov ${ }^{1}$, Andrii Skryl ${ }^{1}$, Yelizaveta Chereshneva ${ }^{2}$, Dibahan Tsomartova ${ }^{2}$, \\ Marina Ivanova ${ }^{2}$, Elina Tsomartova ${ }^{2}$, Diana Shapovalova ${ }^{2}$ and Mariia Pavlova ${ }^{2}$ \\ ${ }^{1}$ Research and Testing Center Cherkizovo Ltd., Feed and animal products quality testing center, Russia \\ ${ }^{2}$ Federal State Autonomous Educational Institution of Higher Education I.M. Sechenov First, Russia
}

*Corresponding author: Sergii Shapovalov, Research and Testing Center Cherkizovo Ltd., Feed and animal products quality testing center, Russia

\section{ARTICLE INFO}

Received: 慧 November 16, 2019

Published: November 26, 2019

Citation: Sergii Shapovalov, Sergei Mikhaylov, Andrii Skry, Yelizaveta Chereshneva, Dibahan Tsomartova, et al. Free Radical Oxidation and Antioxidant Status of Milk from Different Cow Breeds. Biomed J Sci \& Tech Res 23(2)-2019. BJSTR. MS.ID.003871.

\begin{abstract}
The dependence of lipid peroxidation (LP) processes in the milk on cow breed was revealed. The intensity of LP processes is significantly $(p<0.001)$ higher in milk of cows of the red-and-white breed, compared to milk of Simmental and black-and-white cows, with a significantly lower level of Schiff bases. The thioldisulfide status (TDS) of Simmental cows' milk was higher compared to other test groups. A relatively low level of TDS was observed with more intense oxidation processes in the milk of red-and-white cows. Different methods of free radical detection showed that milk from all three breeds retain antioxidative capacity at the concentration of thiobarbituric acid active products up to $550 \mathrm{nM} / \mathrm{ml}$. Obtained results confirmed applicability of tested methods, models and test-systems for the estimation of milk antioxidative status.
\end{abstract}

Keywords: Lipid Peroxidation; Milk; Chemoluminescence; Cow Breeds; Antioxidant Activity

\section{Introduction}

Milk is a unique mix of nutrients containing more than 200 species that are not present in this combination in other human food products. Due to significant number of somatic cells with prevalence of neutrophils, milk is traditionally considered as a highly reduction-oxidation (redox) resistant polycomponent system, consisting of substances possessing antioxidant and health-beneficial features. At the same time, apoptotic death and "respiratory burst" of neutrophils in milk activates a free-radical lipid peroxidation (LP), because of the presence of unsaturated fatty acids. The features of the dynamics of indices, characterizing pro-oxidant-antioxidant homeostasis of milk as a biological fluid on the whole were shown in works of several researchers [1-5]. Nowadays, an approach allowing integration of a great amount of well-known earlier and described recently facts, being fragmented previously, was gained a further development in the concept of biological regulation mechanisms [5]. In particular, the existence of a direct dependence between biochemical reactions and accompanying physiological processes from one side and the redox status of biological system and a surrounding medium was shown by many authors [6-10]. However, the possibility of milk antioxidant effects prolongation by manipulation with cattle genealogy, their feeding, and introduction of antioxidants into the ration, milk and dairy products needs further investigation. Therefore, to shed more light on this question we studied models of the antioxidant status estimation, lipid peroxidation and other oxidative processes in milk of three most widely used breeds of cows.

\section{Materials and Methods}

The plan of research was reviewed and approved by Independent Ethics Committee of the Federal State Budgetary Institution of Science Center for Theoretical Problems of PhysicoChemical Pharmacology of the Russian Academy of Sciences. All the procedures connected with the collection of biological materials were conducted in accordance with recognized ethical standards, norms and regulations of Russian Federation and international laws. The three different groups containing 12 cows in each group were formed at the pedigree farm. The group 
a) Contained only Simmenthal cows, group

b) Contained red-and-white cows, and group

c) Contained black-and-white cows. During the experiment all the cows were in similar housing and feeding conditions. Proand antioxidant (AO) features of milk were investigated in daily milk yield of each group being on the sixth month of lactation, as well as cattle's blood and urine samples. Additionally, the spontaneous and induced H2O2 luminescence was determined in milk. Samples were taken during one week with a two days' interval, in accordance with International Committee for Animal Recording (ICAR) recommendations.

Lipid peroxidation was estimated according to [11] and expressed in $\mathrm{nM} / \mathrm{ml}$, taking the molar extinction' coefficient of pure malondialdehyde (MDA, Sigma Aldrich) equal to $1.56 \cdot 105$. The determination of active products, interacting with thiobarbituric acid (TBA) was carried according to [12].

In short, the method is based on the interaction between MDA and TBA in acid medium at high temperature with the formation of colored trimethine complex, having absorption maximum at 532 $\mathrm{nm}$. The concentration of diene conjugates (DC) extracted from milk was measured at $233 \mathrm{~nm}$ [11]. The mean molecular weight fraction of oligopeptides was determined a follow. At first, the $0.1 \mathrm{M}$ phosphate buffer ( $\mathrm{pH}=7.4$, Sigma Aldrich) was added to a milk in a proportion milk:buffer $1: 10$. After 15 minutes of incubation at $25^{\circ} \mathrm{C}$ proteins were precipitated by a $20 \%$ solution of trichloroacetic acid (TCAA, Sigma Aldrich) with a subsequent centrifugation at 3000 RPM. Finally, the optical density of supernatant fluid diluted with a physiological saline in the proportion 1:1 was determined at wavelengths of 254, 275 and $280 \mathrm{~nm}$ against physiological saline. The free-radical oxidation indexes were measured using chemiluminometer HLM-003. The intensity of $\mathrm{H}_{2} \mathrm{O}_{2}$-induced chemoluminescence was expressed in imp/s. The content of glutathione was estimated according to the [13]. The content of protein sulfhydryl groups in milk was determined according to [14], using the initial protein precipitation by means of perchloric acid followed by solubilization and interaction of sulfhydryl groups with Ellman's reagent (5,5'-dithiobis-(2-nitrobenzoic acid). Total milk antioxidant activity was estimated according to its ability to inhibit the accumulation of TBA-active products of LP under incubation of egg yolk lipoproteins as described in [15]. Lipid antioxidant activity was expressed as percentage of lipoprotein oxidation inhibition by egg yolk lipoproteins. Free-radical oxidation products (diene conjugates, ketodienes, trienes, Schiff's bases) were determined in isopropanol phase of milk at a wavelength of 232, 278 and 400 $\mathrm{nm}$ respectively. The result was expressed in oxidation index units, representing the absorption' ratio of oxidation products relative to independent double bonds number (measured at $220 \mathrm{~nm}$ ), namely E232/220, E278/220 and E400/220.

Statistic parameters were calculated in the accordance with [16]. The data were presented in the form of median and interquartile range from 25 (low quartile) to 75 (high quartile). Comparison between groups was performed using the Mann-Whitney U test, while comparing more than 2 groups, the Kruskal-Wallis test was used [17]. Correlation analysis was performed using Spearman (rS) and Kendel (rK) tests [18]. Differences were considered statistically significant at $\mathrm{p}>0.999$.

\section{Results and Discussion}

After studying the content of free-radical oxidation products, generated at the initial, intermediate and final stages of lipid peroxidation in day milk of cows of different breeds, different levels of their accumulation were revealed (Table 1). The content of TBAactive products is a well-known criterion, reflecting processes of lipid peroxidation both in a body and in biological fluids such as blood, urine, milk, saliva etc. MDA represents $85-90 \%$ of TBAactive products and the rest of them are presented by saturated, unsaturated and aromatic aldehydes, formic acid, glyceraldehydes. The levels of MDA under spontaneous development of lipid peroxidation processes in milk were reliably $(\mathrm{P}>0.999)$ higher in groups (II) and (III) compared to the group (I). The concentration of TBA-active products at $\mathrm{Fe}_{2}{ }^{+-s t i m u l a t e d ~} \mathrm{LP}$ was reliably higher in the milk of the group (II) cows ( $>>0.999)$ compared to the both groups (I) and (III); and reliably lower in the group (I) compared to the group (II) ( $\mathrm{P}>0.999)$. Similar results were obtained while using classical model of initiation and generation of LP by ferrous irons in Fenton's medium. This reaction was modeled as follows:

$$
\hat{\mathrm{F}} e_{2}++\mathrm{H}_{2} \mathrm{O}_{2} \rightarrow \mathrm{Fe}_{3}++\mathrm{OH}-+\mathrm{OH}^{*} \rightarrow-{ }_{2}
$$

The same situation was observed when measuring TBA-active products while modeling multidirectional processes: inhibition and stimulation. It was shown that inhibition by buthylhydroxytoluene and initiation of PL by ascorbic acid in the milk of cows of the group (II) leads to an increase of TBA level compared to other groups $(\mathrm{P}>0.999)$. A high correlation $(\mathrm{r}=-0.95)$ was observed between the TBA-active products' content and the number of oligopeptides, generating as a result of destructive action of reactive oxygen species (ROS). The first components reacting with ROS are most likely the milk lipids giving numerous after-products, including MDA and 4-hydroxynonenal, hydroperoxide diene conjugates, ketodienes and trienes. Therefore, the protein destruction depends not only on ROS level but also on the generated LP after-products, capable to get bounded with proteins, thus modifying their structure. Obtained results showed that the milk from different breeds is characterized by different level of diene conjugates. In particular, it slightly higher in the milk of red-and-white cows, compared to Simmental and black-and-white ones. Interaction of dialdehydes with membrane molecules leads to generation of Schiff's bases (LP final products). The accumulation of latter destabilizes cell membranes, including membranes of polymorphonuclear neutrophils (somatic milk cells) and initiates their destruction. It was shown that the level of Schiff's bases was almost similar in the milk of cows of group (I) and group (III), while it was noticeably higher in the milk of group (II). Such 
phenomenon indicates the activation of LP process, as evidenced by the increase of the TBA-active LP products' level.

The incubation in Fenton's medium generating ROS, as well as with ascorbic acid, leads to an increase of LP products in milk. Close correlation in changes of TBA-active products' content and oligopeptides amount was observed both when comparing different cows' groups and under the initialization of oxidation reactions in vitro ( $r=0.87-0.97)$ (Table 1$)$. The LP products' accumulation (in particular MDA in milk) depends on the peroxidation processes in the mammary gland secretion and on the antioxidant status of tissues, organs and bodily fluids. The increase of MDA concentration testifies to the LP enhancement and "failure" of the antioxidant protection [19]. It was found that MDA concentration (the main TBA-active product) decreases in the row blood serum $>$ urine $>$ lactoserum (Table 2), while stay within limits of a normal physiological level at groups (I) and (III). The group (II) cows demonstrated reliably higher MDA indices in blood serum, urine and lactoserum. This finding is in good agreement with a data on total amount of accumulated TBA-active products (Table 1). To evaluate the free radicals' amount and antioxidant properties of milk the luminol-dependent chemoluminescence was used. The generation of free radicals stimulated by presence of milk' somatic cells can be promoted by an addition of luminol. The latter increases quantum efficiency of the reaction and it leads to a boost in functional activity of leukocytes. This "respiratory burst" results in generation of $-\mathrm{O}_{2}, \mathrm{O}_{2}$ and $\mathrm{OH}^{*}$ [20]. The data on chemoluminescence of combined (daily) milk of cows of different breeds are presented in Table 3. The biggest changes were observed in the group (II) both for rapid and slow flashes. It was found that maximum intensity (Imax) parameter, most likely characterizing the free radicals' amount and thus LP speed, decreases in the row group (II) > group (III) > group (I) (Table $3 \& 4$; Figure 1 ). At the same time the slope of kinetic curve $\left(\operatorname{tg} \alpha_{2}\right)$ is also highest in the group (II), indicating the highest inhibiting property of the product itself. Additionally, a good correlation $(r=0.98)$ between the light sum (S), corresponding to an area under chemoluminescence kinetic curve, and both Imax and $\operatorname{tg} \alpha_{2}$ parameters was found.

Table 1: The content of free-radical lipid and protein oxidation' products in milk of cows of different breeds.

\begin{tabular}{|c|c|c|c|}
\hline & group (I) & group (II) & group (III) \\
\hline TBA-active products, spontaneous LP, nM/ml & $576.5 \pm 11.3$ & $728.3 \pm 12.5^{\mathrm{a}}$ & $610.3 \pm 14.3^{\mathrm{c}}$ \\
\hline TBA-active products, dibutylhydroxytoluene inhibited LP, nM/ml & $55.7 \pm 2.6$ & $71.8 \pm 2.1^{\mathrm{a}}$ & $57.8 \pm 5.5^{c}$ \\
\hline TBA-active products, $\mathrm{Fe}^{2+}$ - dependent LP, nM/ml & $851.0 \pm 10.4$ & $1112.3 \pm 3.1^{\mathrm{a}}$ & $952.3 \pm 12.6^{\mathrm{b}, \mathrm{c}}$ \\
\hline TBA-active products, ascorbic acid dependent LP, nM/ $\mathrm{cm}^{3}$ & $740.7 \pm 11.3$ & $923.6 \pm 5.5^{\mathrm{a}}$ & $757.6 \pm 3.1^{c}$ \\
\hline $\mathrm{MDA}, \mathrm{nM} / \mathrm{ml}$ & $480.5 \pm 12.3$ & $615.3 \pm 32.1^{\mathrm{a}}$ & $515.3 \pm 10.3^{c}$ \\
\hline Diene conjugates, a.u./mg & $0.17 \pm 0.01$ & $0.18 \pm 0.03$ & $0.23 \pm 0.02^{\mathrm{b}}$ \\
\hline Ketodienes, a.u./mg & $0.07 \pm 0.01$ & $0.08 \pm 0.01^{\mathrm{a}}$ & $0.09 \pm 0.01^{\mathrm{b}, \mathrm{c}}$ \\
\hline Optical absorption of oligopeptids at $\lambda=254$, a.u. $/ \mathrm{ml}$ & $0.74 \pm 0.08$ & $0.82 \pm 0.02$ & $0.63 \pm 0.04^{\mathrm{b}}$ \\
\hline Optical absorption of oligopeptids at $\lambda=275$, a.u. $/ \mathrm{ml}$ & $0.21 \pm 0.01$ & $0.20 \pm 0.01$ & $0.18 \pm 0.01^{\mathrm{b}, \mathrm{c}}$ \\
\hline Optical absorption of oligopeptids at $\lambda=280$, a.u. $/ \mathrm{ml}$ & $0.15 \pm 0.01$ & $0.14 \pm 0.01$ & $0.16 \pm 0.01^{c}$ \\
\hline Optical absorption of Schiff's bases (azomethins), a.u./ml & $0.20 \pm 0.01$ & $0.13 \pm 0.01 \mathrm{a}$ & $0.20 \pm 0.01 b$ \\
\hline
\end{tabular}

Note: a - P>0.999 (I to II group), b - P>0.999 (I to III group), c - P>0.999 (II to III group).

Table 2: MDA concentration in lactoserum, blood and urine of cows of different breeds, $\mathrm{nM} / \mathrm{ml}$.

\begin{tabular}{|c|c|c|c|}
\hline & group (I), $\mathbf{n = 6}$ & group (II), n=6 & group (III), n=6 \\
\hline Milk & $576.5 \pm 9.3$ & $728.3 \pm 12.5^{\mathrm{a}}$ & $720.3 \pm 4.3^{\mathrm{b}}$ \\
\hline Blood & $695.6 \pm 10.1^{*}$ & $874.6 \pm 2.3^{\S, \mathrm{a}}$ & $776.2^{*} \pm 2.5^{*, \mathrm{~b}, \mathrm{c}}$ \\
\hline Urine & $640.7 \pm 7.1^{\S, \dagger}$ & $845.7 \pm 12,1^{\S, \dagger, \mathrm{a}}$ & $743.5 \pm 3.7^{\S,+, \mathrm{b}, \mathrm{c}}$ \\
\hline
\end{tabular}

Note 1: accuracy in each group * $\mathrm{P}>0,999$ (lactoserum to blood), $\S$ - $\mathrm{P}>0,999$ (lactoserum to urine), $\uparrow$ - $\mathrm{P}>0,999$ (blood serum to urine).

Note 2: a - P>0,999 (I to II group), b - P>0,999 (I to III group), c - P>0,999 (II to III group).

Table 3: The intensity of Fe2+ -induced chemoluminescence in milk of the cows of different breeds.

\begin{tabular}{|c|c|c|c|}
\hline & group (I) & group (II) & group (III) \\
\hline Intensity of rapid flash $\left(I_{\max }\right), \mathrm{mV}$ & $0.62 \pm 0.01$ & $0.67 \pm 0.05$ & $0.63 \pm 0.01$ \\
\hline Slow flash $(\mathrm{S}), \mathrm{mV} \cdot \mathrm{s}$ & $2.49 \pm 0.03$ & $3.62 \pm 0.07^{\mathrm{a}}$ & $2.96 \pm 0.05^{\mathrm{b}, \mathrm{c}}$ \\
\hline Slope of a curve $\left(\operatorname{tg} \alpha_{2}\right), \mathrm{mV} \cdot \mathrm{s}$ & $-0.16 \pm 0.01$ & $-0.21 \pm 0.02^{\mathrm{a}}$ & $-0.21 \pm 0.04$ \\
\hline Coefficient $\mathrm{K}_{1}\left(I_{\max } / S\right)$ & $0.18 \pm 0.04$ & $0.32 \pm 0.02^{\mathrm{a}}$ & $0.25 \pm 0.01^{\mathrm{c}}$ \\
\hline Coefficient $_{2}\left(\operatorname{tg} \alpha_{2} / \mathrm{S}\right)$ & $0.05 \pm 0.01$ & $0.16 \pm 0.01^{\mathrm{a}}$ & $0.18 \pm 0.01^{\mathrm{b}}$ \\
\hline
\end{tabular}

Note: a - P>0.999 (I to II group), b - P>0.999 (I to III group), c - P>0.999 (II to III group). 
Table 4: The results of chemoluminescence in milk of different cow breeds, taken during a week.

\begin{tabular}{|c|c|c|c|c|}
\hline Observation day & Background & $\begin{array}{l}\text { Background + own } \\
\text { fluorescence }\end{array}$ & $\begin{array}{l}8 \text { minutes' sum spontaneous } \\
\text { fluorescence }\end{array}$ & $\begin{array}{l}8 \text { minutes' sum under } \mathrm{H}_{2} \mathrm{O}_{2} \\
\text { induction }\end{array}$ \\
\hline \multicolumn{5}{|c|}{ group (I), n=6 } \\
\hline $1^{\text {st }}$ day & 6610 & 7593 & 22073 & 97435 \\
\hline $3^{\text {rd }}$ day & 6280 & 7214 & 20969 & 87563 \\
\hline $5^{\text {th }}$ day & 5941 & 6824 & 19838 & 77436 \\
\hline $7^{\text {th }}$ day & 5881 & 6755 & 19639 & 75661 \\
\hline Average $\mathrm{M} \pm \mathrm{m}$ & $6178 \pm 169$ & $7096 \pm 194$ & $20630 \pm 563$ & $84524 \pm 5039$ \\
\hline Limits (min-max) & $5881-6610$ & $6755-7593$ & $19639-22073$ & 75661-97435 \\
\hline Coefficient of variation (CV), \% & 5.5 & 5.5 & 5.5 & 11.9 \\
\hline \multicolumn{5}{|c|}{ group (II), n=6 } \\
\hline $1^{\text {st }}$ day & 7358 & 8352 & 26488 & 99410 \\
\hline $3^{\text {rd }}$ day & 6990 & 7935 & 25164 & 89439 \\
\hline $5^{\text {th }}$ day & 6613 & 7506 & 23805 & 79210 \\
\hline $7^{\text {th }}$ day & 6547 & 7431 & 23567 & 77418 \\
\hline Average $\mathrm{M} \pm \mathrm{m}$ & $6877 \pm 188^{a}$ & $7806 \pm 213^{\mathrm{a}}$ & $24756 \pm 676^{\mathrm{a}}$ & $86302 \pm 5130$ \\
\hline Limits (min-max) & $6547-7358$ & 7431-8352 & $23567-26488$ & 77418-99410 \\
\hline Coefficient of variation (CV), \% & 5.5 & 5.5 & 5.5 & 11.9 \\
\hline \multicolumn{5}{|c|}{ group (III), n=6 } \\
\hline $1^{\text {st }}$ day & 6358 & 7593 & 16555 & 780446 \\
\hline $3^{\text {rd }}$ day & 6040 & 7213 & 15728 & 691425 \\
\hline $5^{\text {th }}$ day & 5714 & 6824 & 14878 & 600082 \\
\hline $7^{\text {th }}$ day & 5657 & 6756 & 14729 & 584088 \\
\hline Average $\mathrm{M} \pm \mathrm{m}$ & $5942 \pm 162^{c}$ & $7096 \pm 194^{c}$ & $15473 \pm 423^{\mathrm{b}, \mathrm{c}}$ & $664010 \pm 45445^{\mathrm{b}, \mathrm{c}}$ \\
\hline Limits (min-max) & $5657-6358$ & $6756-7593$ & $14729-16555$ & $584088-780446$ \\
\hline Coefficient of variation (CV), \% & 5.5 & 5.5 & 5.5 & 13.7 \\
\hline
\end{tabular}

Note: a - P>0.999 (I to II group), b - P>0.999 (I to III group), c - P>0.999 (II to III group).

The further study on artificial generation of ROS using $\mathrm{H}_{2} \mathrm{O}_{2}$ and lipoprotein complexes - yolk suspensions' inductors was carried out to estimate antioxidant properties of milk of different breeds' cows. The chemoluminescence dynamics did not differ significantly during 7 days of observation within test groups. Similarly, to luminol case, the highest $\mathrm{S}$ and Imax were observed in group (II) both for hydroperoxide-induced and own luminescene of milk, compared to other test groups (Table 4). Coefficients of variation (CV) of chemoluminescence indices were practically at the same level regardless of the test group (5.46\% under spontaneous fluorescence and $11-13 \%$ for $\mathrm{H}_{2} \mathrm{O}_{2}$-induced). The results of milk antioxidant properties' estimation in the medium containing egg yolk lipoprotein complexes are shown on Figure 1. The direct correlation between the quantity of added milk and the AO inhibition of lipoprotein oxidation from one side and the increase of photon flash sum from another side can be seen ( $>>0.999)$. Thereby, the milk property to inhibit free-radical oxidation of lipoproteins, lipids and proteins can be supposed. Moreover, this finding suggests the existence of own super weak milk' luminescence, contributing to the increase of photon flash sum. The generation of TBA-active products under spontaneous (without any initiation) lipid peroxidation in milk was found to be a function of photon flash sum (Figure 2). The process starts at $17.10^{3}$ photon flashes and linearly increases in a concentrations range $550-700 \mathrm{nM} / \mathrm{ml}$ to its maximum of $29.10^{3}$ photon flashes, where all the oxidation processes stop. At concentrations lower than 550 $\mathrm{nM} / \mathrm{ml}$ the decrease in lipid peroxidation activity and increase in spontaneous luminescence was observed. Such behavior may indicate the presence of powerful enzymatic echelon of antioxidant protection in milk. In other words, the two opposite processes of lipid peroxidation and antioxidant protection can be observed in milk at the same time.

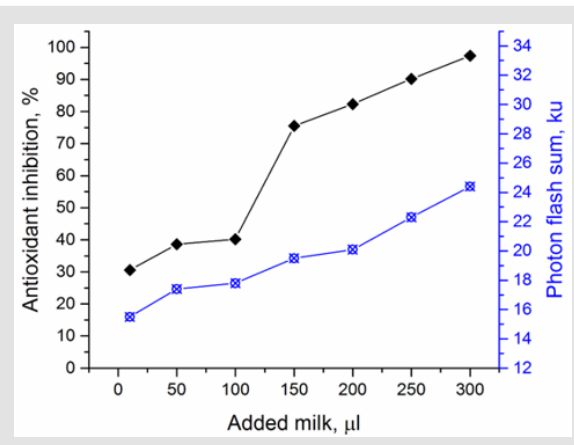

Figure 1: The interrelation between free-radical processes in model system with egg yolk lipoprotein complexes, chemoluminescence and antioxidant features of milk. 


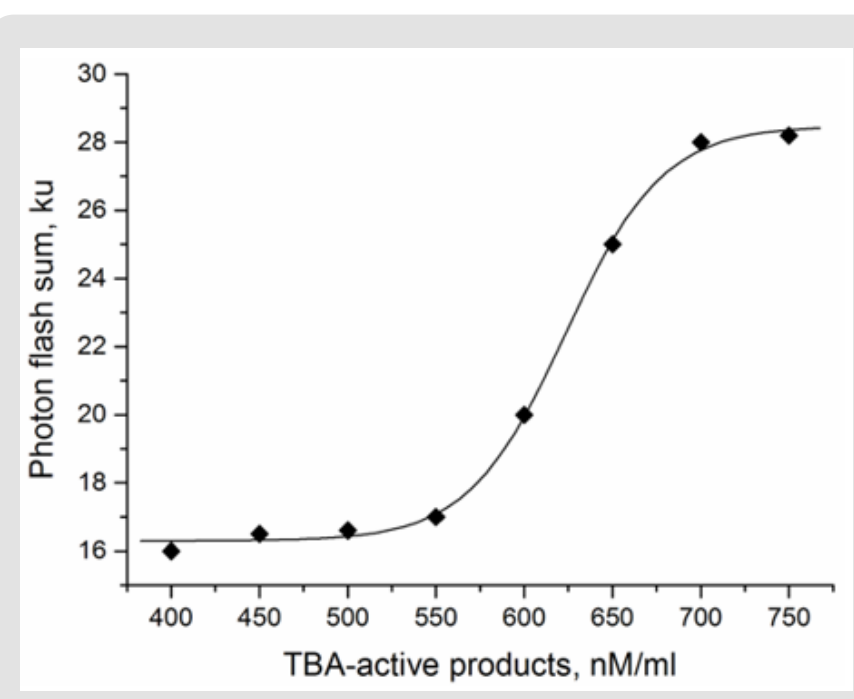

Figure 2: Dependence of chemoluminescence intensity on TBA-active products concentration under spontaneous lipid peroxidation in milk.

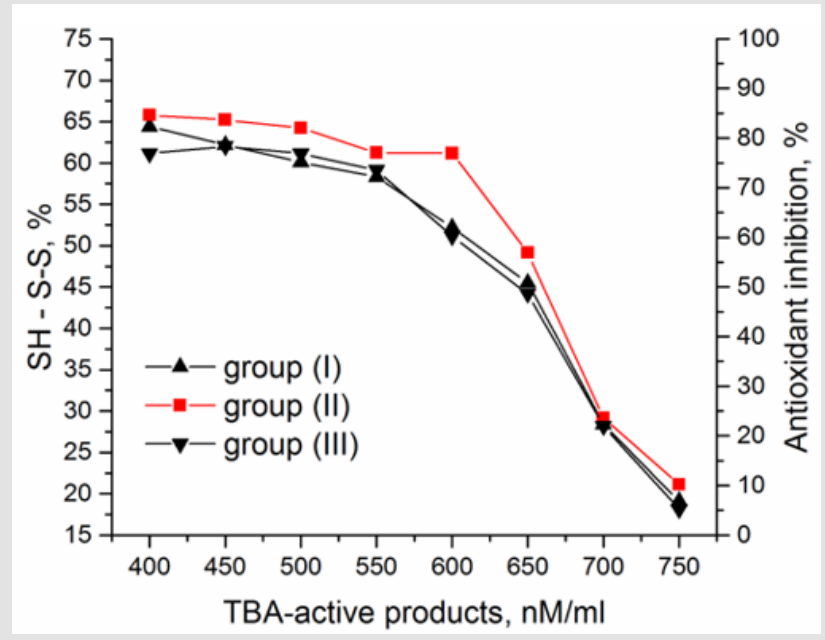

Figure 3: The interrelation between generation of TBAactive products under spontaneous lipid peroxidation in milk and SH-S-S in free SH-groups.

Prolonged activation of LP processes leads to the development of lipid peroxidation syndrome and antioxidant deficiency, demanding timely corrections of these abnormalities in milk by means of introduction of exogenous antioxidants. Enzymatic glutathione redox system plays an important role here. Beside the regulation of protein biosynthesis, participation in processes of cell fission, differentiation and apoptosis, elimination of free radicals, lipid peroxides and hydroperoxides it takes part in SH - S-S exchange. In this study we used the thiol to disulphide groups' ratio to estimate the antioxidant inhibition and the status of antioxidant protection in a whole (Figure 3). It was found that at concentrations of TBAactive products up to $550 \mathrm{nM} / \mathrm{mlSH}$-groups lead to an increase of AO inhibition. At the same time, at higher concentrations of TBA-active products the content of reduced glutathione decreases, causing the decrease in $\mathrm{AO}$ inhibition. Thus, the generation of oxidative stress under the accumulation of TBA-active products higher than 550 $\mathrm{nM} / \mathrm{ml}$ induces the decrease in redox status of milk. According to the value of SH-S-S status it can be arranged (from highest to lowest) in the row: group (II) > group (I) > group (III). However, after reaching the TBA-active products concentration higher than $650 \mathrm{nM} / \mathrm{ml}$, the SH - S-S status and AO inhibition become practically the same in all milk. Such phenomenon can be explained by the fact that free radicals primarily attack the weakest bonds, i.e. hydrogen bonds in protein and other molecules. The presence of much easier oxidizable glutathione SH-groups protects proteins from oxidative modification. Therefore, initiation and maintenance the reactions leading to the preservation of reduced thiol equivalents in milk increases the resistance to lipid peroxidation (Figure 4). The significant correlation $r=0.888,0.741$ and 0.656 was found between concentration of polyunsaturated fatty acids (PUFA) and chemoluminescence intensity, LP products activated by $\mathrm{Fe}^{2+}$ and spontaneously developed LP products respectively (Figure 5).

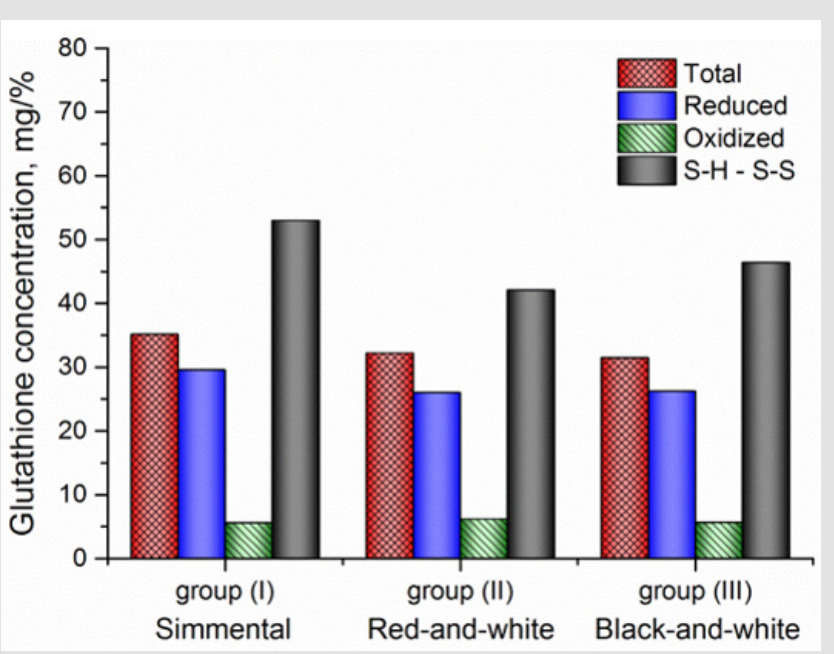

Figure 4: Glutathione concentration comparing to SH-S-S in free $\mathrm{SH}$-groups.

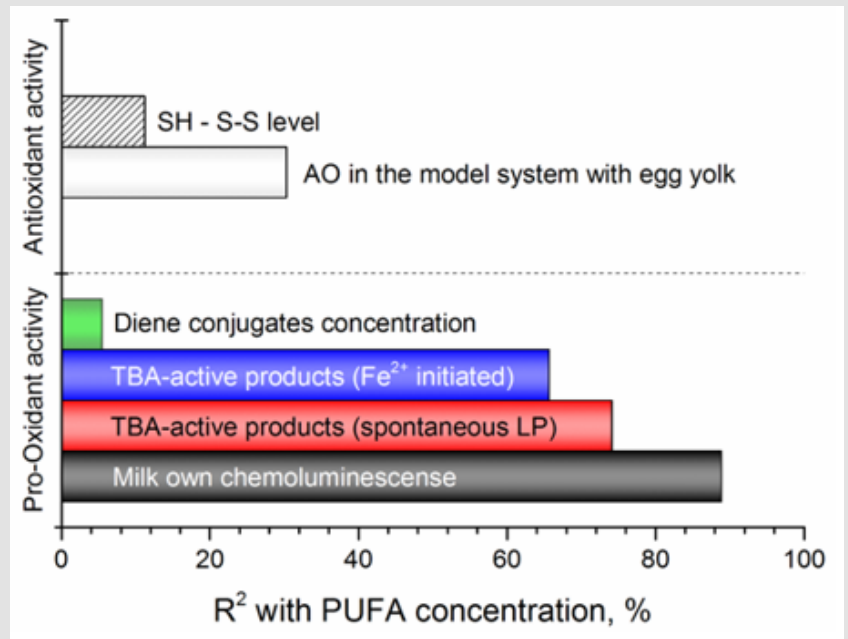

Figure 5: Interrelation between polyunsaturated fatty acids (PUFA) concentration and indices of milk pro- and antioxidant activity. 


\section{Conclusion}

The dependence of lipid peroxidation processes on the concentration of polyunsaturated fatty acids in milk lipids was investigated. The milk of red-and-white cows demonstrated slightly higher level of diene conjugates, compared to Simmental and blackand-white cows. Azomethin concentration (Schiff base) in the final LP products was at the level $0.126-0.200 \mathrm{a} . \mathrm{u} . / \mathrm{ml}$. The dependence between total flash of photons and the amount of oxidation after products (TBA-active products) was shown. The significant correlation was found between concentration of polyunsaturated fatty acids and chemoluminescence intensity. The interrelation between SH - S-S status of the milk and antioxidant inhibition was demonstrated.

\section{References}

1. Trevisan M (2001) Correlates of Markers of Oxidative Status in the General Population. American Journal of Epidemiology 154(4): 348-356

2. Agarwal A, S Gupta, RK Sharma (2005) Role of oxidative stress in female reproduction. Reproductive Biology and Endocrinology 3(1): 28.

3. Halliwell B, JM Gutteridge (2015) Free radicals in biology and medicine. 2015: Oxford University Press, USA.

4. Jóźwik A (2010) The oxidative status of milking goats after per os administration of $\mathrm{N}$-acetylcysteine. Animal Science Papers and Reports 28(2): 143-152.

5. Jóźwik A (2012) Relationship between milk yield, stage of lactation, and some blood serum metabolic parameters of dairy cows. Czech Journal of Animal Science 57(8): 353-360.

6. Suzuki YJ, L Packer (1995) Redox regulation of DNA-Protein Interactions by biothiols, in Methods in Enzymology. Academic Press Pp: 175-180.

7. Sen CK (1998) Redox Signaling and the Emerging Therapeutic Potential of Thiol Antioxidants. Biochemical Pharmacology 55(11): 1747-1758.

8. Moran LK, J Gutteridge, GJ Quinlan (2001) Thiols in Cellular Redox Signalling and Control. Current Medicinal Chemistry 8(7): 763-772.

ISSN: 2574-1241

DOI: 10.26717/BJSTR.2019.23.003871

Sergii Shapovalov. Biomed J Sci \& Tech Res

(c) (P) This work is licensed under Creative Commons Attribution 4.0 License

Submission Link: https://biomedres.us/submit-manuscript.php
9. Daynes RA, EY Enioutina, DC Jones (2003) Role of Redox Imbalance in the Molecular Mechanisms Responsible for Immunosenescence. Antioxidants \& Redox Signaling 5(5): 537-548.

10. Nakamura H (2004) Thioredoxin as a Key Molecule in Redox Signaling Antioxidants \& Redox Signaling, 6(1): 15-17.

11. Ohkawa H, N Ohishi, K Yagi (1979) Assay for lipid peroxides in animal tissues by thiobarbituric acid reaction. Analytical Biochemistry 95(2): 351-358.

12. Balthazary S, HP Sallmann, H Fuhrmann (1999) The determination of TBA-Reactive substances and alkenals in the presence of antioxidants. Acta Veterinaria Hungarica 47(2): 155-159.

13. Tipple TE, LK Rogers (2012) Methods for the Determination of Plasma or Tissue Glutathione Levels. in Developmental Toxicology: Methods and Protocols. 889: 315-324.

14. Bellomo G, H Thor, S Orrenius (1990) Modulation of cellular glutathione and protein thiol status during quinone metabolism, in Methods in Enzymology 186: 627-635.

15. Nikolaevskil AN (2006) Testing of the antioxidant activity of substances using gasometric method of determination of egg yolk lipoproteins oxidation. Biomeditsinskaia khimiia 52(2): 211-218.

16. Snedecor GW, WG Cochran (1989) Statistical methods. In: Snedecor GW, WG Cochran (Eds.), ( $8^{\text {th }}$ edn.). Ames: Iowa State Univ. Press Iowa.

17. Gubler E, A Genkin (1973) Application of nonparametric criteria of statistics in medicobiological researches. L Medicina pp. 141.

18. Bolboaca SD, L Jäntschi (2006) Pearson versus Spearman, Kendall's tau correlation analysis on structure-activity relationships of biologic active compounds. Leonardo Journal of Sciences 5(9): 179-200.

19. Ayala A, MF Muñoz, S Argüelles (2014) Lipid Peroxidation: Production, Metabolism, and Signaling Mechanisms of Malondialdehyde and 4-Hydroxy-2-Nonenal. Oxidative Medicine and Cellular Longevity 2014: 31.

20. Mehrzad J (2001) Respiratory burst activity of blood and milk neutrophils in dairy cows during different stages of lactation. Journal of Dairy Research 68(3): 399-415.

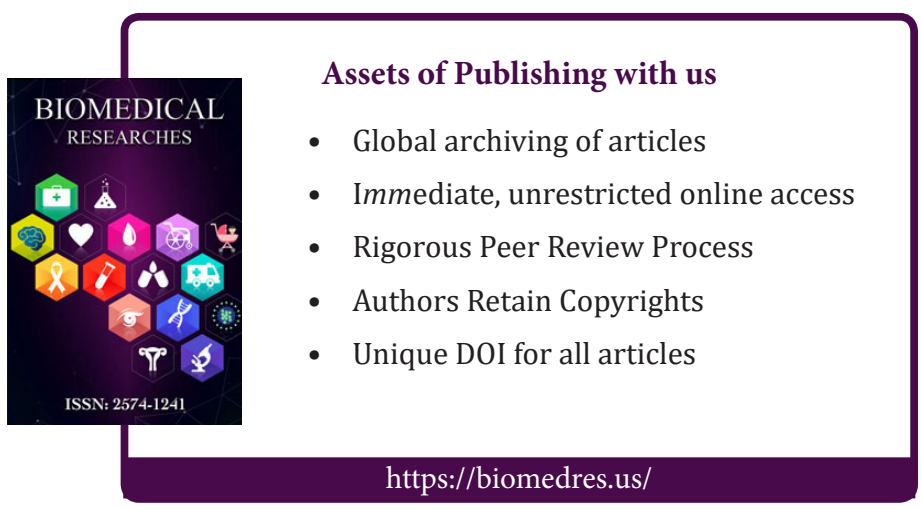

